\title{
O IMAGINÁRIO RELIGIOSO NA OBRA “OPERÁRIOS DE PRIMEIRA HORA" DE VALDEMAR MAZZURANA SOB A PERSPECTIVA DO REGIME NOTURNO DAS IMAGENS
}

\author{
Heloisa Juncklaus Preis Moraes ${ }^{1}$ \\ Luiza Liene Bressan²
}

\section{INTRODUÇÃO}

A religiosidade dos italianos era algo muito particular, especialmente para aquela população camponesa migrante, analfabeta, em sua grande maioria. Confiar nos destinos traçados por Deus era a forma de se fortalecerem e de se unirem. A religião católica era seu leme. Era ela que ordenava seu mundo e Ihes permitia encontrar significado na experiência pela qual estavam passando, apesar das dificuldades encontradas. Acreditar em Deus constituía-se como necessidade balizadora do fazer do imigrante italiano no sentido de vencer as agruras impostas pela natureza que lhe era hostil e transmutar de sua cultura para uma outra realidade.

Assim, na narrativa em que nos baseamos para produzir este estudo, a personagem de Salvino Mazzamurelli procura se desvencilhar das amarras deixadas na Itália, quando se envolvera com entidades obscuras. No Brasil, o trabalho duro no cultivo da terra poderia servir para obscurecer a presença constante do homenzinho de vermelho que o acompanha desde a saída da Itália. O patriarca da família crê que afastar o filho e alterar seu nome para vir à América o livrará da perseguição do homenzinho de vermelho. No entanto, o ente acompanha toda a trajetória vivenciada pela personagem, entre gozos e escárnios, que sugerem uma configuração do regime noturno das imagens, descrito por Durand (2012).

\section{O REGIME NOTURNO DAS IMAGENS}

\footnotetext{
${ }^{1}$ Doutora. Docente do Programa de Pós Graduação em Ciências da Linguagem da Universidade do sul de Santa Catarina. heloisapreis@hotmail.com

${ }_{2}$ Mestre. Docente do Centro Universitário Barriga Verde. luizalb@yahoo.com.br
} 
Opondo-se ao regime diurno cujas forças são antagônicas e uma prevalece sobre a outra, o regime noturno constitui-se de forças unificadoras e harmonizantes (PITTA, 2005). Estas forças são harmonizadas de duas formas diferentes que correspondem as duas estruturas do imaginário: a mística e a sintética. Neste regime a queda heroica se transforma em descida e o abismo em receptáculo. Assim, ascender ao poder não é o objetivo maior e sim descer à procura do conhecimento. "O regime noturno da imagem estará constantemente sob o signo da conversão e do eufemismo" (DURAND, 2012, p.197).

O imaginário possui uma estrutura mística, compreendida, aqui, no sentido durandiano cuja significação é a "construção de uma harmonia" na qual se conjugam uma vontade de união e certo gosto pela secreta intimidade (PITTA, 2005).

Para que o objetivo da harmonização seja alcançado, Durand (2012) arrola símbolos cuja significação minimiza as expressões mais duras e chocantes. Assim, o estudioso do imaginário explicita os símbolos de inversão, constituído pela expressão do eufemismo que abranda o conteúdo angustiante, trazendo certo alívio às dores universais por se caracterizar pela ambiguidade, pelo sentido plural que alimenta e fecunda a palavra. (PITTA, 2005). Ainda, ao estudar os símbolos de inversão, Durand (2012) se reporta ao encaixamento e redobramento, que recriam imagens de engolimento do outro para apropriação de essências. Cita como um dos exemplos o caso das bonecas russas em que a maior contém as menores. Outro símbolo de inversão é o hino à noite, entendida com o avesso do dia, divinizada, hora do encontro, da reunião. É a noite onde as águas banham-se de lua, adquirindo a cor prata, simbolizando o feminino, a fecundidade. Outro símbolo de inversão é a mater e matéria, representando as grandes mães aquáticas cuja simbologia dos longos cabelos aludem ao aquático e ao telúrico como se "as águas fossem as mães do mundo, enquanto a terra seria a mãe dos vivos e dos homens".

O regime noturno também comporta os símbolos da intimidade, representados pelo túmulo e o repouso, recompensa da vida agitada e atribulada. $A$ moradia e a taça compõem também símbolos da intimidade. São figurativas (metonímia: o continente pelo conteúdo) e daí decorre o isomorfismo da casa antropomorfa descrita por Bachelard cujo sótão é a cabeça e o porão, as raízes (PITTA, 2005). Compondo os símbolos que se referem à intimidade, componentes místicos durandianos, temos os alimentos e substâncias. A substância é a 
intimidade da matéria e "toda alimentação é trans-substanciação", pois o alimento é transformado em energia ao modificar sua essência (PITTA, 2005). Aqui, também são apresentados os alimentos arquetípico como o leite, relacionado ao afeto significativo da amamentação, o mel, as bebidas sagradas, o sal.

Estes componentes místicos do imaginário amenizam a angústia existencial e a morte, negando suas existências e possibilitando vislumbrar um universo harmonioso no aconchego e no íntimo de si mesmo e das coisas.

No regime noturno também há a estrutura sintética do imaginário em que o tempo é positivo, compreendendo-o como o movimento cíclico do destino e da tendência ascendente do progresso do mesmo. Nesta estrutura do imaginário estão agrupados os símbolos cíclicos, relacionados a fenômenos naturais e/ou culturais, como é o caso do ciclo lunar que organiza, em função de suas fases, o tempo em diversas culturas. Compõe também os símbolos cíclicos a espiral, relacionado ao permanente movimento e que sugere o equilíbrio dos contrários. A simbologia da serpente (ofidiano) também traz em sua essência o ideia do tempo, pois três são as dimensões significativas, a saber: transformação temporal pela troca de pele; a da representação do ciclo por meio do uroboros (a serpente mordendo a própria cauda) e o aspecto fálico, relacionado à maestria nas águas e à fecundidade. Outro símbolo relacionado ao regime noturno e à estrutura sintética do imaginário é a tecnologia, pois os objetos, artefatos são cíclicos e representam o tempo e o destino da humanidade. Aqui, os arquétipos da roda são engrenagens arquetipal que alavancaram a imaginação humana. É o "scheme rítmico ao mito do progresso". Também é um forte símbolo o sentido da árvore que, em sua verticalidade, semelhante à humana, permite passar do devaneio cíclico para o devaneio progressista. A árvore simboliza a vida e por suas constantes e sucessivas transformações e por sua humanização resume a verticalidade e o cósmico, assim como o ser humano. Na árvore há a sugestão do devir e a progressão do tempo.

Assim, o sintetismo estrutural do imaginário procura harmonizar os contrários, construindo com eles e a partir deles um diálogo cuja finalidade é salvaguardar as diferenças e contradições, propondo um percurso histórico e de progresso.

\section{PROCEDIMENTOS MITODOLÓGICOS}


Durand propõe a mitodologia (metodologia desenvolvida por ele) para estudarmos a ocorrência de imagens simbólicas nos fenômenos culturais e seus prolongamentos. Por compreender particularidades em quatro âmbitos históricos, culturais e sociais, o imaginário e a mitodologia se tornam adequados para os estudos que envolvem as narrativas literárias, objeto deste estudo.

A mitodologia de Durand é dividida em mitocrítica e mitanálise, em que: na mitocrítica as imagens simbólicas de um material cultural são catalogadas em redundâncias e repetidas de forma constante, por isso, são identificadas; na mitanálise se busca identificar mitos que trabalham a sociedade profundamente, buscando compreender os contextos em que essas repetições incessantes acontecem, sendo a mitanálise um complemento da mitocrítica. Compreendida desta maneira, a mitocrítica parte de um contexto cultural e a mitanálise parte do contexto social. Como o cultural e o social são imbricados, ao se analisar aspectos culturais, aparecem os aspectos sociais.

Valendo-nos destes aspectos metodológicos da mitodologia proposta por Durand, naveguemos, então, pelo universo religioso presente dos "Operários de Primeira Hora", buscando na narrativa as marcas da religiosidade a partir do regime noturno das imagens.

\section{O IMAGINÁRIO RELIGIOSO DE OS OPERÁRIOS DE PRIMEIRA HORA}

A narrativa, objeto desta análise, procura reconstruir a saga de imigrantes italianos à busca da cocanha em solo brasileiro, na imaginal Brentano. Dentre os que embarcaram rumo a esta colônia, havia aqueles que vinham em busca de oportunidades e, outros cuja viagem era uma fuga, talvez de um passado de que não quisessem lembrar. Os esperançosos alimentavam-se na fé cristã, invocando Deus e venerando os santos da igreja católica. Tinham como meta erguer a capela e se preocupavam com a presença de um padre em celebrações festivas e/ou fúnebres.

Entretanto, uma personagem chama atenção na narrativa. Trata-se de Salvino Mazzamurelli, um dos filhos de Marco Barca. Envolvido em uma seita secreta, embarca com este nome, objetivando fugir dos compromissos assumidos 
com esta organização. Deixa para trás o espaço, mas carrega a história que se manifesta em forma de uma imagem sarcástica a debochar de sua fuga.

\begin{abstract}
Quando caminhava, com a família, pelo convés do navio, percebeu um homem muito baixinho, um anão, o menor de todos os que já havia visto, todo vestido de vermelho, que se posicionava na proa. Subiu no posto mais alto. Sentou-se num assento de madeira lá existente, dobrou as pernas à moda Buda. O homenzinho quase passou despercebido, mas olhava fixamente para Salvino, com um olhar de revolta e desaprovação. O estranho ser começou a fazer trejeitos, movendo as sobrancelhas espessas para cima e para baixo; arredondando os lábios volumosos, sacudindo alternadamente as orelhas altas e pontudas, fazendo gestos bruscos e inesperados com as mãos relativamente grandes e grossas, parecendo querer assustar quem o olhava (MAZZURANA, 2012, p.63).
\end{abstract}

A imagem descrita é um símbolo que vai acompanhar a trajetória da vida da identidade de Salvino. Entende-se, pois, o símbolo como a representação que faz aparecer um sentido que pode ser, simultaneamente, cósmico, onírico ou poético e revelar-se, ao mesmo tempo, como significante (forma) e significado (sentido), manifestando-se como linguagem em suas várias formas e significações míticas (DURAND, 1993).

O mito do homenzinho vermelho na narrativa de Mazzurana nos revela que todas as alterações que a narrativa mítica sofre, sinalizam para as suas potencialidades criadoras, que se refletem no diálogo estabelecido entre o mito e a sociedade. Afinal, que mito se faz representar no homenzinho de vermelho que persegue Salvino?

Mazzurana (2012, p.247) assim resolve o enigma do homenzinho vermelho, de orelhas pontudas que persegue Salvino ao longo de sua trajetória desde o embarque na Itália e em toda sua vida em Brentano.

O segredo era referente ao nome: Salvino Mazzamurelli.

Ah! - Fez o padre. - Mazzamurelli. Então este não é o teu nome verdadeiro! - Foi um rolo criado para emigrar.

- Mazzamurelli... Teu pai te colocou este nome sem saber que Mazzamurelli é nome de propriedade do outro mundo, o mundo dos espíritos, duendes e fadas... (Pausa). Claro! Claro! Uma agressão! (Pausa). O padre tinha lido os documentos de Concílio de Trento e estremeceu.

E, na narrativa, o padre continua lhe orientando como deve proceder para se livrar da perseguição implacável do homenzinho: "Disse que as crenças em duendes, fadas, bruxas e outras figuras mágicas estavam condenadas pela igreja e que se existissem, estavam relegadas ao fogo do inferno, conforme declara 0 Concilio de Trento, ressaltou" (MAZZURANA, 2012, p. 248). 
Como o retorno era uma utopia, Salvino teve de conviver ainda por muito tempo com a perseguição implacável que recebia do duende do mal. Outro fato importante, na narrativa de Mazzurana, relacionada à personagem de Salvino, foi a vinda ao Brasil de Carmelino Malacarne, descendente do principal comprador de terras no antigo continente, responsável pela miséria de muitos dos trabalhadores de primeira hora, que para fugir da miséria na pátria mãe Itália, vendiam o pouco que tinham ao mercenário comprador de terras. Esta personagem procura pelo filho de Marco Barca, Fintano Barca. O que não sabe que este tem um nome falso, desde a saída do país de origem. Investiga os mais antigos, mas nada descobre.

Depois de algum tempo, um episódio deixaria toda Brentano em alvoroço. A casa alugada por Carmelino Malacarne pega fogo e ele é declarado morto no incêndio. No entanto, entre as cinzas da casa, jamais foram encontrados seus restos mortais. Uma vizinha declarou tê-lo vista em casa de terno e que só usava esta roupa quando pretendia viajar.

Depois disso, Salvino sentia-se em paz, até que um episódio desencadeado pelo furto de um garrafão de vinho, atribuído ao homenzinho vermelho que neste pareceu-Ihe amistoso, nas palavras de Mazzurana (2012, p.311312):

Mas, de repente, a atmosfera vibrou, passou por ele uma onda de ar frio, os bichos gritaram assustados, as nuvens se retorceram e o homenzinho vermelho apareceu lá na beira do mato que Salvino tinha reservado para fazer sombra aos animais, nos dias de sol quente e para proteger a nascente de onde retirava água para a família. Pois lá estava ele, ele mesmo, aquele que tanto o importunara na vida, mas que, nos últimos tempos, parecia ter-se afastado um pouco, talvez contente por estar adaptado à vida americana e ter acertado com Curupira a metade (um pouco mais!) do reino das florestas onde viviam italianos. Salvino estranhou que $o$ pequeno ser não soltara aquela gargalhada impertinente $e$ persistente, tão sonora que retumbava pelos matos, colinas e montanhas que o cercavam e o humilhava. Pelo contrário, o homenzinho vermelho, pela primeira vez, parecia querer se comunicar com Salvino, inclinava-se, fazia gestos amáveis como se quisesse externar agradecimento.

Salvino considerou este gesto um deboche e o episódio o fez procurar novamente a figura de um padre para tentar resolver o mistério. Ao narrar-lhe os fatos, o padre o orientou para que deixasse sempre oferendas para contentar 0 homenzinho vermelho. Cabe dizer que a este sacerdote, Salvino omitiu sua origem e o nome trocado. Feliz com a proposta Salvino retorno à casa e a encontra vazia, pois a esposa havia saído e seus filhos, já casados, moravam no centro de Brentano. Mas o conselho do padre em tornar o duende num aliado fez de Salvino 
um homem mais feliz e chegou a cantarolar pequenos versos ao duende: "Folletto, folletto, tu sei mio amico, non sei diavoletto"!

O simbolismo do homenzinho vermelho desaparece com Salvino, mas coexiste na narrativa dos imigrantes italianos do sul de Santa Catarina de Mazzurana, pois, conforme Morin (1999) há outros aspectos do conceito mitológico que também podem ser atribuídos a uma questão discursiva, inseparável da linguagem. O pensamento mitológico carrega consigo um conjunto simbólico, de condição imaginária e eventualmente com traços da realidade. Dessa forma, a narrativa mítica não só fala de situações vinculadas aos atributos criacionistas de um povo ou localidade, mas também se refere a traços de sua identidade, seu futuro e até de sua aspiração. Em geral, as narrativas dos mitos "transformam a história de uma comunidade, cidade, povo; tornam-na lendária e, geralmente, tendem a duplicar tudo o que acontece no mundo real e no mundo imaginário para ligá-los e projetá-los no mundo mitológico" (MORIN, 1999, p. 175).

\section{CONSIDERAÇÕES FINAIS}

A fictícia Brentano, suas personagens, seus medos e sua religiosidade estão bem marcados na narrativa mazzuraniana. Estes símbolos religiosos, mitos e ritos e as suas convergências, organizações, ou constelações, são o foco da iniciação à imaginação simbólica. Portanto, compreendemos que o ponto focal da leitura do fenômeno religioso na narrativa simbólica de Mazzurana se entende a partir do imaginário, onde a imagem transita simbolicamente, entre um inconsciente e a consciência.

Qualquer manifestação da imagem representa uma espécie de intermediário entre um inconsciente não manifesto e uma tomada de consciência ativa. Daí ela possuir o status de um símbolo e constituir o modelo de um pensamento indireto no qual um significante ativo remete a um significado obscuro (DURAND, 1993, p. 36).

A tomada de consciência que a imaginação é simbólica e onde o imaginário não age independente da razão, que os símbolos conseguem epifanizar o inexplicável, sendo o símbolo da natureza do signo. Somente pelo imaginário é possível compreender a simbologia do homenzinho de vermelho e o desaparecimento de Salvino. Assim, é possível concluir que a interpretação simbólica, de cunho instaurador, fundamentado por Durand, pode significativamente proporcionar uma compreensão do fenômeno religioso, entendendo que o mesmo 
consiste em uma manifestação simbólica e que os símbolos são das categorias do imaginário.

\section{REFERÊNCIAS}

DURAND, Gilbert. As estruturas antropológicas do imaginário. São Paulo: Martins Fontes, 2012.

. Campos do Imaginário. Textos reunidos por Danièle Chauvin. Grenoble: Ellug, 1996.

A Imaginação Simbólica. 6 ed. Lisboa: Edições 70, 1993.

MAZZURANA, Valdemar M. Operários da Primeira Hora. Palhoça: Editora da Unisul, 2012.

MORIN, Edgar. O Método 3- o conhecimento do conhecimento. Porto Alegre: sulina, 1999.

PITTA, Danielle P. Rocha. Iniciação à teoria do Imaginário de Gilbert Durand. Rio de Janeiro: Atlântica, 2005. 